\title{
Evaluating the City Image: A Focus on Landmarks of Kuala Lumpur, Malaysia
}

\author{
Ahmed Raad Al-Shams ${ }^{1}$ \& Nurwati Badarulzaman ${ }^{2}$ \\ ${ }^{1}$ Architectural Department, Engineering Collage, Basrah University, Iraq \\ ${ }^{2}$ School of Housing, Building and Planning, Universiti Sains Malaysia, Malaysia \\ Correspondence: Ahmed Raad Al-Shams, Architectural Department, Engineering Collage, Basrah University, \\ Iraq. E-mail: ahmedalshams@gmail.com
}

\author{
Received: October 23, 2013 Accepted: November 26, 2013 Online Published: January 26, 2014 \\ doi:10.5539/ass.v10n4p241 \\ URL: http://dx.doi.org/10.5539/ass.v10n4p241
}

\begin{abstract}
One of the main issues that have been considered about Kuala Lumpur city is its indistinguishable identity and image, partly due to the rapid development and expansion of the city structure over many decades. Inevitably, forming a distinctive city image is not an easy task as it depends primarily on the manner of reciprocal interactions between people and their surrounding built environment. This paper examines the relationship and interaction between people and the city structure, specifically through public evaluation of landmarks as one of the five elements of the city image. The people's background and their evaluation of the landmarks' features are examined in this study. To achieve this objective, both quantitative and qualitative data were collected using mixed-techniques involving a questionnaire survey of 120 respondents followed by an unstructured interview. The results show significant differences in the public evaluation of landmarks based on the respondents' nationality and ethnicity. Differences in the evaluation are related to the landmark factors namely unique; memorable; legible; historic; design; scale; meaningful and color. Much effort by the local authorities is necessary to create a distinguishable image of Kuala Lumpur that reflects the city's fusion of modern and traditional lifestyles, and diversified cultures and values.
\end{abstract}

Keywords: Kuala Lumpur, city image, landmarks, public evaluation

\section{Introduction}

In the last decades, there has been a growing awareness of the cities' role as a center of development, innovation, culture and regional economic growth (Jansson \& Power, 2006). This is further supported by the local authorities' emphasis on creating and maintaining a distinctive city image as part of the agenda for global competitiveness, and to boost cities as the center of international events to attract more investors and tourists.

Malaysia as one of the rapidly developing countries has grown markedly in terms of population and urbanization (Thompson, 2007). So much so that some of the local and traditional Malaysian urban environments are being replaced gradually by modern structures and standardized images of global universal characteristics that may not be appropriate to the local cultural expressions, traditions and way of life (Ujang, 2008). Issues on impact of globalization take center stage in the visions of Kuala Lumpur to become a world-class city by 2020. One of the main goals of the Kuala Lumpur Structure Plan is "To create a distinctive city identity and image through reflecting its multi-cultural society and its rich history" (Kuala Lumpur Structure Plan, 2020, p. 33).

This paper examines the contemporary city image of Kuala Lumpur as presented, through the public evaluation of landmarks as one of the city image elements. To achieve this objective, hypotheses are tested to determine if there is any significant difference in the evaluation of city landmarks among the respondents in terms of their nationality (foreign tourist or local); ethnicity (Malay, Chinese, Indian or other ethnic); gender; age group; and educational level. Findings from this study will contribute in improving the image of Kuala Lumpur city and its landmarks, thus enhancing a sense of identity of the city and its people.

\section{Literature Framework}

The term "City Image" as first defined by Kevin Lynch in his book The Image of the City is "a result of a two-way process between the observer and his environment, the environment suggests distinctions and relations, and the observer-with great adaptability and in the light of his own purpose-selects, organizes, and endows with 
meaning what he sees." (Lynch, 1960, p. 6). The adaptability of the observer depends on his perception as well as his dealings with the surrounding environment. The perception influences and shapes the mental image of the observer by way of keeping the attractive and important elements of the city in their mind (Atik, Çakir, \& Benian, 2009).

Admittedly, human interaction with the surrounding environment differs from one person to another depending on his background and his needs from the city. Each person essentially develops a different view and perception. However, this perception is not all encompassing of the surrounding environment, but it partial in nature and mixed with other relevant concerns of respective individuals (Lynch, 1960).

By the same token, the mental image of the same area may vary significantly between different observers (Lynch, 1960; Atik, Çakir, \& Benian, 2009), because it is not a result of immediate perceptions only, but it is a product of both immediate sensation and the past experiences embedded in multifold personal memories and meanings (Lynch, 1960). This concept of perception requires a two-way process between two complementary views to form the notion of a city image. One is the physical aspect, related to the physical form of the city; and another is perceptual, referring to the way that the observer interacts with the physical form of the city. Moreover, this process is affected by the critical third dimension of time, which forms the city image simply by engaging more human interactions in the city space, leading to enhanced experiences and intense feelings of belonging and attachment (Zmudzinska, 2003). Hence, it is observed that people are able to recall places that they have strong feelings and association with (Nasar, 1990).

It is noteworthy that building a city image requires ample time and strategy to achieve its target. During the process of forming and promoting the image of a city, a good image may be distorted due to some unfortunate events, which lead to difficulties in restoring the intended images in the people's minds (Gavris, 2010). A city image is important because it contributes in forming the perceptions of the observers (or inhabitants), their level of tastes and behaviors; as well as the languages and range of notions that the observers' possess about their surrounding environment (Zmudzinska, 2003).

Thus, a distinctive city image helps the observer to establish a harmonious relationship between self and the surrounding environment, and gives a personal feeling of familiarity and emotional security (Lynch, 1960). This positive sensation of familiarity and security exude a feeling of comfort and acquaintance amongst the visitors and tourists when they visit a city for the first time.

\subsection{Landmark as an Element of City Image}

Kevin Lynch's study on three American cities: Boston, New Jersey and Los Angeles for five years led to his theory of city image. He identified five elements of city image (namely path, edge, district, node and landmark), but in reality all of them are related and cannot exist in isolation, where "districts are structured with nodes, defined by edges, penetrated by paths, and sprinkled with landmarks" (Lynch, 1960, p. 49).

Based on Lynch's work, this paper identifies landmark as an element of city image to be evaluated by the observers (local people and tourists) in Kuala Lumpur. This is due to the importance of landmark as a symbol that relates and represents the quality of the place, depth of tradition and culture with an enhanced significance over time (Clerici \& Mironowicz, 2009). Lynch defines landmark as an element with distinctive spatial features, which are visible from many angles and distances, over the tops of smaller elements, and used as radial reference to help people to orientate or find their way in the surrounding environment. The key aspects of landmarks are to be unique, memorable in the context, with a scene of a historic event (Lynch, 1960).

Moughtin defined landmark as an element or a group of coherent elements that can be singled out against a landscape background of repetitive detail (Moughtin et al., 1999). In addition, landmark may be physically or spiritually unique, influential, impressive, and commonly recognized by the people as a sign of place and direction (Hasanuddin, 2004). Nevertheless, none of these urban features can be considered as a landmark without being legible (Clerici \& Mironowicz, 2009).

A common use of landmarks fosters a relationship between them and the people through a feeling of belonging that extends over social and cultural divisions (Gavris, 2010). This interaction formulates the meaning of landmarks based on the general knowledge and common language (Clerici \& Mironowicz, 2009). Passini (1992) suggested that any object even a fountain with a particular meaning can be a landmark. Hence, the literature identifies eight important criteria in considering an urban feature as a landmark, namely unique; memorable; legible (can be seen from many angles); historic; design; scale (over the top of small elements); meaningful and color. All landmarks have some identity, values and meanings to establish communication with the observer. Therefore, it is very important to protect and retain such identity, values and meanings from any significant 
transformation or disturbance (Clerici \& Mironowicz, 2009).

\subsection{Malaysian City Image}

Malaysian cities have developed through many stages from the pre-colonial, colonial period, independence and recently urbanization. At all stages, the concern for identity and cultural representation has been raised, especially in recent decades as Malaysia strives to achieve a developed nation status by 2020 while retaining its distinctive identity, culture and traditions. Indeed, during the pre-colonial period, there was no clear image of the Malaysian settlements, which functioned mainly as ports for trading and sea transport along the Straits of Malacca (Evers \& Korff, 2000). In contrast, the British colonial period left a strong impact on the Malaysian urban centers, through distinct administrative buildings as a legacy of colonial bureaucracy. These buildings remain until today as prominent and visible elements of Malaysian cities (Moser, 2009).

After independence, there were attempts to develop a distinctive image of Malaysian cities, especially in Kuala Lumpur, for two main reasons. Firstly, is to reflect a new image away from its colonial history (Lim \& Tay, 2000); and secondly, to present Malaysia as a modern Islamic country (Moser, 2009).

The first attempt started in 1957 with a major shift from colonial rule to nationalization following the rise of the international architectural movements which depicted clear international style geometries, decorative sub-shading and landscape settings in a 'tropical idiom' (Lim \& Tay, 2000). However, this international modernist urban design and architecture were considered by many as a western cultural import (Moser, 2009).

While, the second attempt started in the 1980s with former Prime Minister Mahathir's nationalist vision through a list of mega projects intended to showcase Malaysia as a modern and efficient country committed to a new model of economic development (Moser, 2009). Putrajaya is a clear example of this vision. However, the design of Putrajaya has been criticized due to its influence and inspiration from an imagined architecture of the Middle East (Moser, 2009; King, 2007).

Generally, these new development have been insensitive to their context and do not integrate successfully with the surroundings, which caused a loss of historical continuum and lacking in a sense of identity (Kuala Lumpur Structure Plan, 2020, p. 14). This situation invariably obliterates the historic assets which are precious and meaningful to the community (Shamsuddin \& Ujang, 2008), with a few notable exceptions.

\section{Methodological Framework}

The mixed-techniques were used as a main approach in this study to evaluate Kuala Lumpur's city image through collecting relevant quantitative and qualitative data. For both data types, a deductive research method was chosen to test the hypotheses and answer the study objectives. The study aims to determine the interactions between the public and their surrounding environment, and the factors affecting such interactions.

To collect the quantitative data, a questionnaire was developed based on previous studies and literature review on people's evaluation of their surrounding built environment. On the other hand, the qualitative data was collected using unstructured interviews with the same respondents who participated in the questionnaire to emphasize in-depth descriptions of their mental image, and knowledge about Kuala Lumpur's landmarks and the surrounding environment. The qualitative data compliments the quantitative data by providing focused, interpretive, detailed descriptions and interpretations of participants (Kritsonis, 2008).

The collected data was analyzed by two methods. The SPSS statistical program was used to analyze the questionnaire, while, the unstructured interviews data was gathered, compared, analyzed for detailed evaluation. The using of mixed-techniques in collecting and analyzing the data helps in strengthening the findings and filling the gaps of each method if it was used individually.

\subsection{Case Study of Kuala Lumpur}

Since the 19th century, Kuala Lumpur city which is located at the confluence of the Klang and Gombak rivers, has been the administrative center of the Federated Malay States, and then the capital of Malaysia after independence in 1957 (Bunnell, Barter, \& Morshidi, 2002). Through the 1960s and 1970s, Kuala Lumpur has witnessed rapid growth in its population and urbanization, similar to most cities of the developing world. The priority was to create wealth and play an important global role without much emphasis on its multi-cultures, traditions and ethnics (Kuala Lumpur Structure Plan, 2020, p. 14). This unbalanced growth is reflected on the city's architecture (Ravenscroft, 2009) with changes in time towards modern city image and skyline.

However, despite intense urbanization pressure over the decades, Kuala Lumpur still retains a wide array of historic buildings of distinct architectural styles and periods, in heritage areas that are reminiscence of its past (Kuala Lumpur Structure Plan, 2020, p. 8). The rich historical development of Kuala Lumpur provides the 
justification for a case study of the Kuala Lumpur city centre.

The Draft Kuala Lumpur City Plan 2020 has divided Kuala Lumpur city centre into three heritage zones, namely Primary, Secondary and Tertiary Heritage Zones. The Primary Heritage Zone is a major area containing many historic buildings gazetted under the National Heritage Act 2005 (formerly the Antiquities Act, 1976). Therefore, it was chosen as the study area because of the significant values and architectural styles of its buildings. In addition, it presents images of the original part of the city as well as modern buildings of different periods and architectural styles, such as the Dayabumi Complex, National Mosque and Agro Bank building. Six major view corridors (or entrances) penetrate the primary heritage zone (Kuala Lumpur Structure Plan, 2020, p. 14), as shown in Figure 1 from A to F. The Kuala Lumpur Railway Station (Entrance F) is a major entry point for train passengers arriving from the north and south regions of Malaysia.

Based on the Draft Kuala Lumpur City Plan 2020, and The Encyclopedia of Malaysia Architecture (Volume 5) (2007), seventeen landmarks of various architectural styles and periods were included in the questionnaire to be evaluated by the respondents. Figures 2 and 3 show the geographical locations of these 17 landmarks, in addition Table 1 gives a summary for each of them.

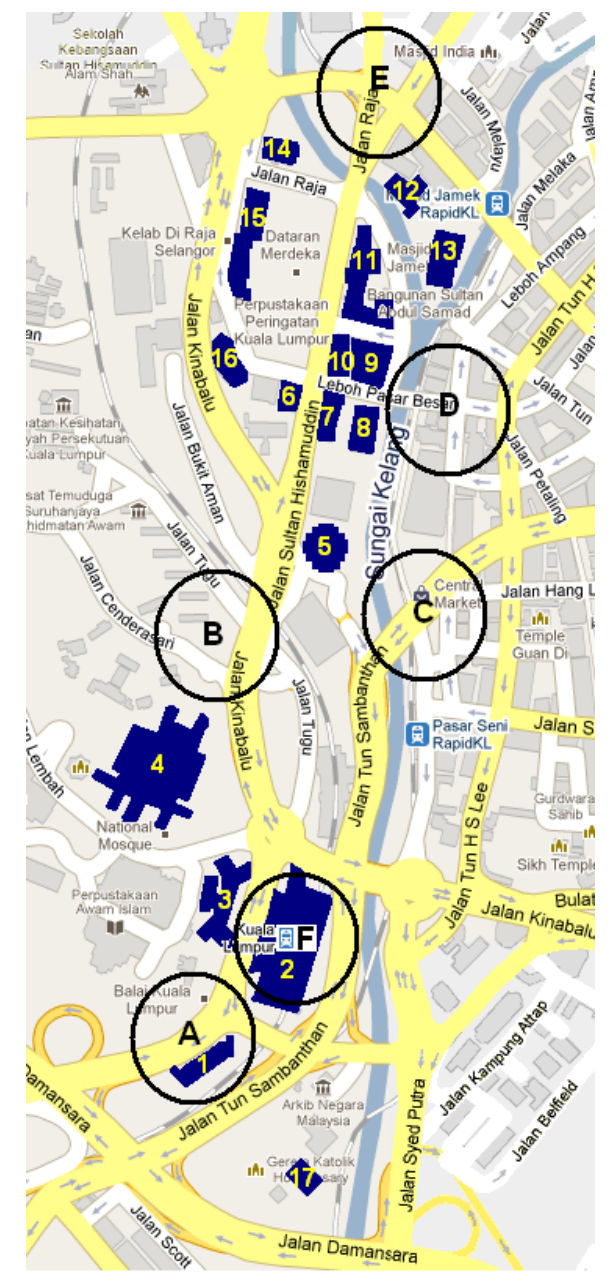

Figure 1. Location of landmarks and major entrances to the study area in Kuala Lumpur Source: Google maps 


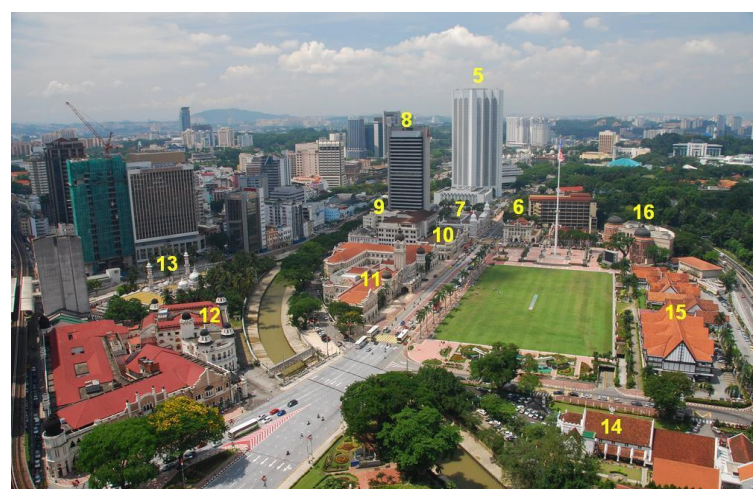

Figure 2. Landmarks in the north part of Kuala Lumpur

Source: Skyscraper website

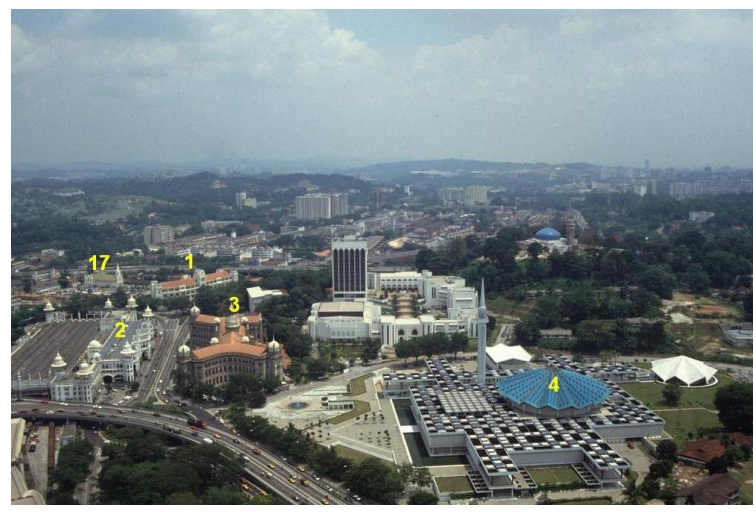

Figure 3. Landmarks in the south part of Kuala Lumpur

Source: Skyscraper website

Table 1. Landmarks located in the Primary Heritage Zone of Kuala Lumpur that included in the questionnaire

\begin{tabular}{llll}
\hline Landmark (1) & Landmark (2) & Landmark (3) & Landmark (4) \\
\hline Syariah Court \\
Colonial Style. (1933), \\
Kandmark (5)
\end{tabular}




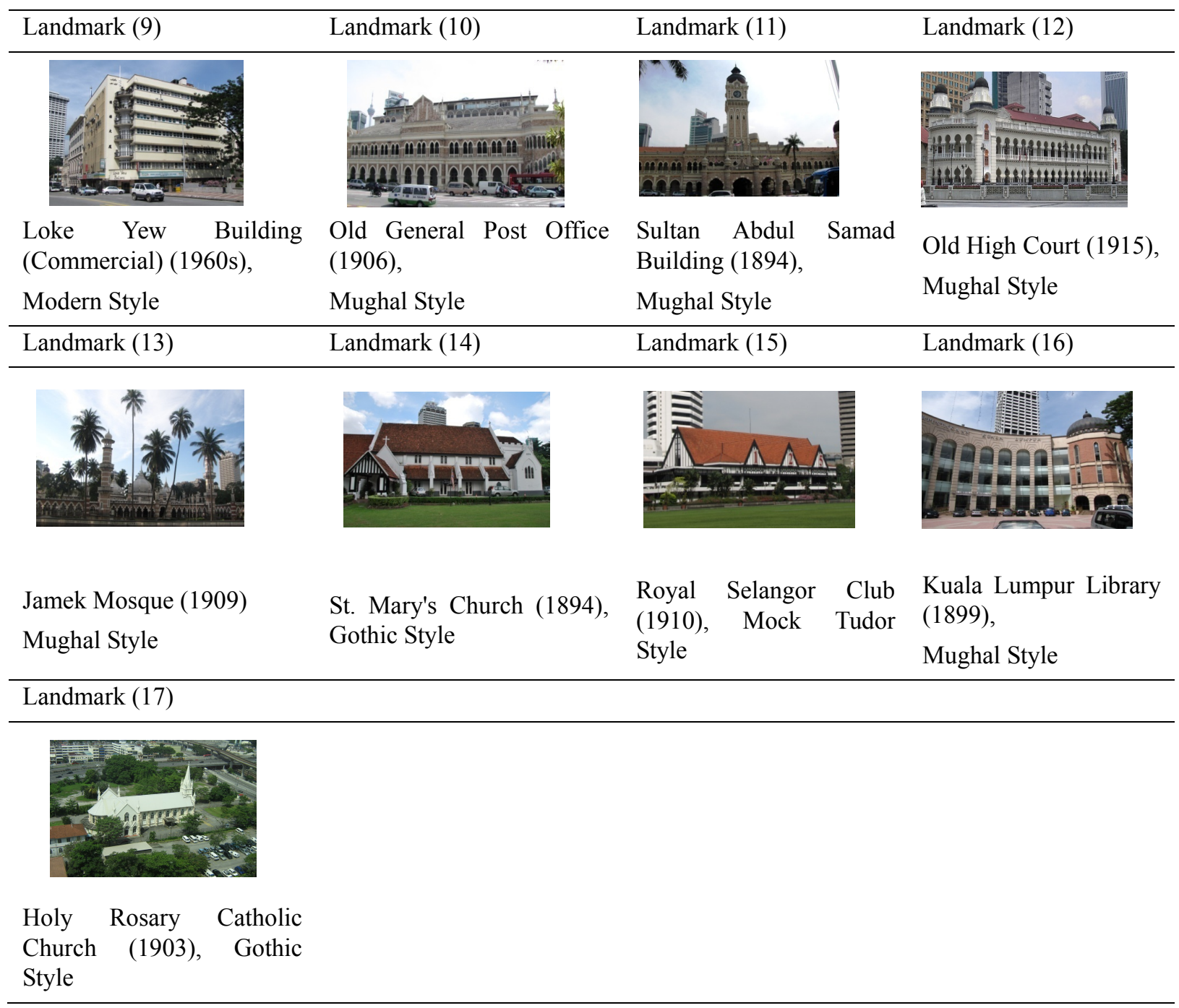

\subsection{Survey Instrument}

The questionnaire used in this study aimed to identify those physical and sensorial features that affect public evaluation of landmarks in Kuala Lumpur. It contains two sections. Section One records the respondents' background such as place of origin, ethnicity, gender, age and educational level, whilst, Section Two has two evaluation stages. In the first stage, each of the respondents was shown pictures of the seventeen landmarks at random, without mentioning any detail to avoid possible biasness. Then, the respondents were asked to evaluate on how well these landmarks represent the original image of Kuala Lumpur using a 4-scaled measure of "Very Strongly to Very Poorly" (refer Figure 4).

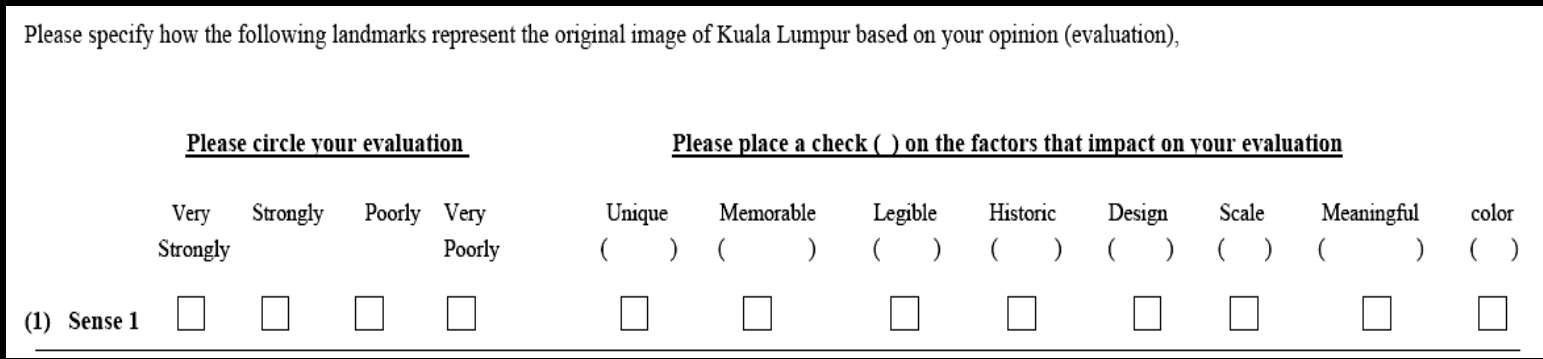

Figure 4. Questions on the respondents' evaluation of the landmarks in the questionnaire 
In the second stage, the respondents were asked to identify which of the factors were influential in their evaluation of the respective landmarks. As discussed earlier, the eight factors or criteria of a landmark are unique; memorable; legible; historic; design; scale; meaningful and color. The questionnaire survey is followed up by an interview session with the same respondents to solicit their deep opinions and reflections pertaining to the factors influencing their evaluation of the landmarks.

Responses of "Very Strongly" and "Strongly" indicate that the landmark represents the original image of Kuala Lumpur positively. While, responses of "Poorly" and "Very Poorly" indicate that the landmark represents the original image of Kuala Lumpur negatively. Therefore, the evaluation is ranged from Very Strongly (value=2), Strongly (value=1), Poorly (value $=-1$ ) to Very Poorly (value $=-2$ ). In addition, the factor value is calculated by multiply 1 if the factor had been chosen; or multiply 0 if the factor had not been chosen by the evaluation value $(2,1,-1,-2)$.

\subsection{Sampling}

A total of 120 respondents participated in this questionnaire survey using the convenience sampling method. In terms of sampling, it is difficult to determine the size of population within the study area because the Primary Heritage Zone is an open area accessible to all people. Therefore, determining the sampling size was based on the methods employed in previous studies of similar research field.

For instance, Lynch (1960) used 100 respondents for each of the three cities in his study. A study of evaluating landmarks of Ayvalik city in Turkey used 120 respondents (Koseoglu \& Odener, 2009). Other studies of place attachment and traditional streets in Kuala Lumpur used a sample size was 110 respondents respectively (Ujang, 2008; Ja'afar \& Usman, 2009). Therefore, this research surveyed 120 respondents distributed equally at the six main entrances of the study area (Askari, 2009). Moreover, the research employed a non-probability sampling method using the "time interval" technique (Ujang, 2008) to collect the data from respondents within the study area.

\section{Results and Discussions}

Data for this study was collected between $24^{\text {th }}$ of December 2010 to the end of January 2011, involving 120 respondents in a face-to-face survey and interview techniques. From the respondents' profile, 84 respondents (70\%) were local, whilst 36 respondents (30\%) were tourists mainly from Asia and Europe. Among the locals, 52 respondents (61.9\%) were Malay, 17 respondents $(20.2 \%)$ were Indian and 15 respondents were Chinese (17.9\%). Gender-wise, 91 respondents $(75.8 \%)$ were male, and 29 respondents $(24.4 \%)$ were female. Most respondents (82 people) were young under 34 years old (68.3\%) In terms of educational level, 57 respondents (48.4\%) had high school education or a diploma. Another 41 respondents (34.7\%) had a Bachelor degree, whilst 20 respondents $(16.9 \%)$ had at least a Masters level education.

\subsection{Evaluation of Landmarks}

Historic landmarks allow the people to interact with the surrounding environment and develop a sense of bonding with the landmark itself and with each other through a mutual sense of belonging, which extends over social and cultural divisions (Gavris, 2010). This study aims to identify which historic landmarks of Kuala Lumpur exude a strong sense of belonging to the people, as solicited through the evaluation survey. Table 2 presents the mean score of the respondents' evaluation of the seventeen landmarks, which in their respective views represent the original image of Kuala Lumpur. The table shows that Jamek Mosque has the highest mean score of 3.62, followed by the Sultan Abdul Samad building (3.57); and the Kuala Lumpur Railway Station building (3.48). On the contrary, the Agro Building and Loke Yew buildings both scored rather low at 2.40 and 2.28 , respectively.

Table 2. Mean score of respondents' evaluation of landmarks

\begin{tabular}{lll}
\hline Rank & Landmark & Mean Score \\
\hline 1 & Jamek Mosque & 3.62 \\
2 & Sultan Abdul Samad Building & 3.57 \\
3 & Kuala Lumpur Railway Station & 3.48 \\
4 & National Textile Museum & 3.47 \\
5 & KTMB Headquarters Railway Administrative Building & 3.42 \\
\hline
\end{tabular}




\begin{tabular}{lll}
\hline Rank & Landmark & Mean Score \\
\hline 6 & Old High Court & 3.40 \\
7 & Dayabumi Complex & 3.39 \\
8 & National Mosque & 3.23 \\
9 & Old General Post Office & 3.22 \\
10 & Kuala Lumpur Library & 3.22 \\
11 & Royal Selangor Club & 3.12 \\
12 & National History Museum & 3.07 \\
13 & Holy Rosary Catholic Church & 2.96 \\
14 & St. Mary's Church & 2.91 \\
15 & Syariah Court & 2.77 \\
16 & Agro Bank Building & 2.40 \\
17 & Loke Yew Building & 2.28 \\
\hline
\end{tabular}

Based on the varying mean scores in Table 2, this study examined those factors that contribute in making the Jamek Mosque as the building that best represents the original image of Kuala Lumpur. A correlation analysis between the respondents' evaluation and the landmark factors showed that Jamek Mosque had the highest evaluation scores in terms of its uniqueness, historical account, design of Mughal architectural style, and meaningful features. The Jamek Mosque (1909) was the first mosque built-in Kuala Lumpur and notably, daily prayers are held in this mosque until today.

Results from interviews with the respondents revealed that the location of the Jamek Mosque at the convergence of the Klang and Gombak rivers gives it a distinct feature as a landmark for locating or orienting the places and destinations for both locals and tourists. Comparative analysis in Table 2 showed that the National Mosque received a lower evaluation score (3.23) than Jamek Mosque (3.62). The interview session showed that comparatively the respondents did not regard the National Mosque as a unique and historic landmark of Kuala Lumpur.

The Sultan Abdul Samad building, National Textile Museum and the Old General Post Office are all located next to each other on the same row in the Merdeka Square. Table 2 shows that the Sultan Abdual Samad Building received the second highest evaluation mean score of 3.57, followed by the National Textile Museum (3.47) and Old General Post Office (3.22). Analysis showed that historic, design, and uniqueness were the main factors that had an impact on the respondents' evaluation of these three landmarks.

Interview results showed that the Sultan Abdul Samad building was regarded as the primary landmark in the Merdeka Square. Since the National Textile Museum and Old General Post Office bear similar design and color with that of the Sultan Abdul Samad building, many respondents apparently assumed that these three buildings were actually a single building. As mentioned by Lynch (1960) a landmark needs to be in contrast with the surrounding environment in terms of design, color, and scale to be unique and recognizable by the people.

An evaluation of two modern buildings, Dayabumi and Agro Bank that are located close to each other also showed big difference in the mean score. Dayabumi has a higher mean score of 3.39 than Agro Bank at 2.40. Dayabumi's design and uniqueness factors were evaluated positively by the respondents; however the same factors produced a negative evaluation on Agro Bank from the respondents. This indicates that a modern designed building may create a distinctive city image but it should be a unique enough to stand out within its surroundings. Dayabumi's modern architectural style with its outstanding scale and color creates a notable landmark even for the first-time tourists to Kuala Lumpur.

\subsection{Hypotheses Testing on Evaluation of Landmarks}

In this study, five hypotheses were tested to determine any significant difference in the evaluation of city landmarks by the respondents in terms of their nationality (foreign tourist or local); ethnicity; gender; age group; and educational level. Results indicated that only 2 hypotheses were accepted. The first accepted hypothesis indicates a significant difference in evaluating landmarks based on nationality. Foreign tourists and local people were significantly different in their evaluations of 16 out of 17 landmarks, and the differences refer to four 
factors which are: unique, historic, memorable and meaningful (refer Table 3). Factors of design and legible had limited impact, while factors of scale and colour had no any impact at all by respondents' nationality.

Table 3. Significant differences in evaluating the 17 landmarks according to nationality

\begin{tabular}{|c|c|c|c|c|c|c|c|c|c|}
\hline \multirow{2}{*}{ Landmarks } & \multirow{2}{*}{$\begin{array}{l}\text { Significant } \\
\text { differences } \\
\text { according } \\
\text { to } \\
\text { Nationality } \\
(\mathbf{p}<\mathbf{0 . 0 5})\end{array}$} & \multicolumn{8}{|c|}{$\begin{array}{l}\text { Factors impacts on the differences between tourists and local significantly } \\
(\mathbf{p}<0.05) \text {. }\end{array}$} \\
\hline & & Unique & Memorable & Legible & Historic & Design & Scale & Meaningful & Color \\
\hline $\begin{array}{l}\text { Jamek } \\
\text { Mosque }\end{array}$ & 0.013 & 0.007 & 0.009 & & 0.003 & & & 0.03 & \\
\hline $\begin{array}{l}\text { Sultan } \\
\text { Abdul } \\
\text { Samad B. }\end{array}$ & 0.000 & 0.000 & & & 0.000 & & & 0.014 & \\
\hline $\begin{array}{l}\text { KL Railway } \\
\text { Station }\end{array}$ & 0.001 & & 0.001 & & 0.002 & & & & \\
\hline $\begin{array}{l}\text { National } \\
\text { Textile } \\
\text { Museum }\end{array}$ & 0.001 & 0.001 & 0.000 & & 0.000 & & & 0.000 & \\
\hline $\begin{array}{l}\text { KTMB HQ } \\
\text { Railway } \\
\text { Adm. }\end{array}$ & 0.001 & 0.001 & 0.001 & 0.038 & 0.008 & 0.015 & & 0.013 & \\
\hline $\begin{array}{l}\text { Old High } \\
\text { Court }\end{array}$ & 0.003 & 0.000 & & & & & & 0.005 & \\
\hline $\begin{array}{l}\text { National } \\
\text { Mosque }\end{array}$ & 0.003 & 0.012 & & & 0.019 & & & & \\
\hline $\begin{array}{l}\text { Old General } \\
\text { Post Office }\end{array}$ & 0.003 & 0.000 & 0.014 & & 0.000 & & & & \\
\hline $\begin{array}{l}\text { Kuala } \\
\text { Lumpur } \\
\text { Library }\end{array}$ & 0.002 & 0.010 & 0.041 & 0.007 & & & & 0.005 & \\
\hline $\begin{array}{l}\text { Royal } \\
\text { Selangor } \\
\text { Club }\end{array}$ & 0.000 & 0.001 & 0.027 & & 0.000 & & & 0.006 & \\
\hline $\begin{array}{l}\text { National } \\
\text { History } \\
\text { Museum }\end{array}$ & 0.010 & & 0.030 & & 0.002 & & & & \\
\hline $\begin{array}{l}\text { Rosary } \\
\text { Catholic } \\
\text { Church }\end{array}$ & 0.025 & 0.002 & & 0.040 & & & & & \\
\hline $\begin{array}{l}\text { St. Mary's } \\
\text { Church }\end{array}$ & 0.000 & 0.007 & 0.042 & & 0.016 & & & & \\
\hline $\begin{array}{l}\text { Syariah } \\
\text { Court }\end{array}$ & 0.003 & & 0.001 & & & & & & \\
\hline $\begin{array}{l}\text { Agro Bank } \\
\text { Building }\end{array}$ & 0.039 & & & & & 0.012 & & & \\
\hline $\begin{array}{l}\text { Loke Yew } \\
\text { Building }\end{array}$ & 0.001 & & 0.013 & 0.027 & 0.027 & 0.001 & & & \\
\hline
\end{tabular}


The second accepted hypothesis indicates a significant difference in evaluating of landmarks based on ethnicity. The significant difference among ethnic groups was evident in the evaluation of 10 out of 17 landmarks, especially in the "meaningful" factor (refer Table 4). Other factors have little impact on the evaluation of landmarks according to ethnicity. The other seven landmarks that got similar evaluation according to the ethnicity are national landmarks such as Jamek Mosque, Sultan Abdul Samad Building, and Kuala Lumpur Railway Station.

Table 4. Significant differences in evaluating the 17 landmarks according to ethnicity

\begin{tabular}{|c|c|c|c|c|c|c|c|c|c|}
\hline \multirow{2}{*}{ Landmarks } & \multirow{2}{*}{$\begin{array}{l}\text { Significant } \\
\text { differences } \\
\text { according } \\
\text { to } \\
\text { Ethnicity } \\
(\mathbf{p}<0.05)\end{array}$} & \multicolumn{2}{|c|}{$\begin{array}{l}\text { Factors impacts on } \\
(p<0.05)\end{array}$} & \multicolumn{2}{|c|}{ the differences } & \multirow{2}{*}{$\begin{array}{l}\text { mong } \mathbf{E} \\
\text { Design }\end{array}$} & \multicolumn{2}{|c|}{ thnic Groups Sign } & \multirow[b]{2}{*}{ Colo } \\
\hline & & Unique & Memorable & Legible & Historic & & Scale & Meaningful & \\
\hline $\begin{array}{l}\text { National } \\
\text { Textile } \\
\text { Museum }\end{array}$ & 0.000 & & & & & & & & \\
\hline $\begin{array}{l}\text { Old High } \\
\text { Court }\end{array}$ & 0.003 & & 0.006 & 0.004 & & & 0.01 & & \\
\hline $\begin{array}{l}\text { National } \\
\text { Mosque }\end{array}$ & 0.001 & & & & & & & 0.001 & \\
\hline $\begin{array}{l}\text { Kuala } \\
\text { Lumpur } \\
\text { Library }\end{array}$ & 0.012 & & & 0.032 & & & & & \\
\hline $\begin{array}{l}\text { Royal } \\
\text { Selangor } \\
\text { Club }\end{array}$ & 0.048 & & & & & & & 0.003 & \\
\hline $\begin{array}{l}\text { National } \\
\text { History } \\
\text { Museum }\end{array}$ & 0.001 & & & & & & & 0.021 & \\
\hline $\begin{array}{l}\text { Holy } \\
\text { Rosary } \\
\text { Catholic } \\
\text { Church }\end{array}$ & 0.028 & & 0.024 & & & & & 0.021 & \\
\hline $\begin{array}{l}\text { Syariah } \\
\text { Court }\end{array}$ & 0.000 & & & & 0.035 & & 0.034 & & \\
\hline $\begin{array}{l}\text { Agro Bank } \\
\text { Building }\end{array}$ & 0.008 & & & & & & & 0.001 & \\
\hline $\begin{array}{l}\text { Loke Yew } \\
\text { Building }\end{array}$ & 0.004 & & & & & & & 0.001 & \\
\hline
\end{tabular}

The study found no significant differences in the evaluation of landmarks by gender; age group; and educational level. Similar finding was found in a German study, where the results indicated some differences according to gender and age groups in their evaluation and remembering of landmarks, but not as strong as was expected (Birgit, Volker \& Marcel, 2009).

\subsection{Importance of Landmark Factors}

Results of the respondents' evaluation of the 17 landmarks showed that the design factor was chosen as the most influential factor in the evaluation of landmarks (1019 counts or $53.5 \%$ of responses). This is followed by historic (1022 counts; 50\%), uniqueness (832 counts; 40.8\%), memorable (721 counts; 35.4\%) and meaningful (517 counts; $25.3 \%)$. However, color (263 counts; $12.9 \%)$, legibility (218 counts; $10.7 \%)$ and scale (215 counts; $10.5 \%$ ) were recorded as the least influential factors on landmarks (Figure 5) (Note 1). 


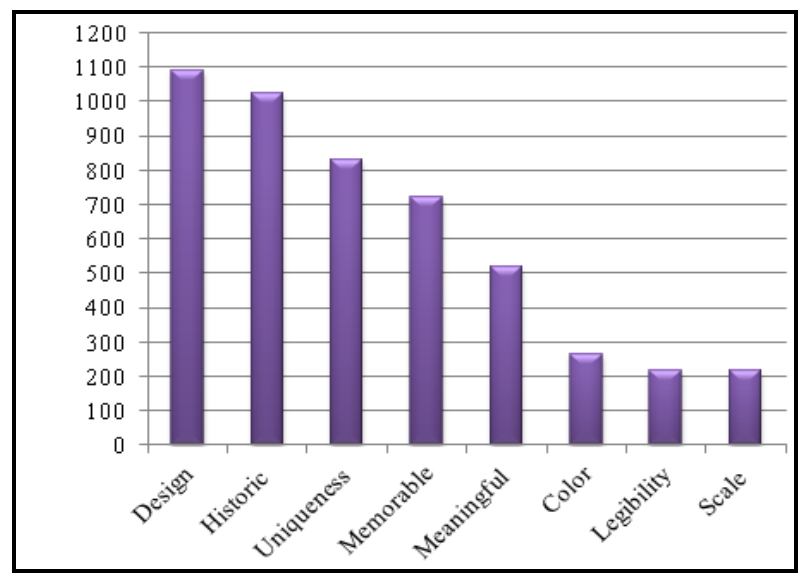

Figure 5. Frequency of important factors in evaluating the landmarks

1) Design: The design factor received the highest score in the evaluation of the Dayabumi Complex, followed by Jamek Mosque and Sultan Abdul Samad building. The Dayabumi's unique architectural style may represent an original image of Kuala Lumpur as supported by some of the respondents' comments during the interviews:

a) A young Malay female said: "The new design of the building can present KL not only the domes and so on."

b) An elderly male tourist from England said: "Dayabumi, new building but related to KL."

c) A young tourist from New Zealand said: "It (Dayabumi) is really unique, I like it."

Although buildings such as Agro Bank and Loke Yew have a modern design, they recorded the lowest scores on the design factor. According to a Chinese tourist, the design of Agro Bank building was not unique as it can be seen anywhere in the city, and it did not represent the original image of Kuala Lumpur. On the other hand, the Mughal architectural styles of Jamek Mosque and Sultan Abdul Samad Building could represent an original image of Kuala Lumpur since they had higher scores on the design factor.

2) Historic: The historic factor was the second most influential factor in the respondents' evaluation of the landmarks and recorded the highest scores in the evaluation of Sultan Abdul Samad Building, Kuala Lumpur Railway Station and Jamek Mosque. The historic factor is embedded in landmarks from long periods of interactions between people and the building. It exudes a feeling of belonging, and a sense of connection between the building throughout the history of the city or the people's past. All these aspects create the identity of the place and build the image of the city.

Sultan Abdul Samad Building, Kuala Lumpur Railway Station and Jamek Mosque were built over 100 years ago and had witnessed many importance events. For instance, the Independence of Malaysia 1957 took place in front of Sultan Abdul Samad Building. Moreover, there is a long history of daily movements throughout the Kuala Lumpur Railway Station or daily prayers held at the Jamek Mosque. Such long-term interaction that exists between the building and people through an original activity bring a deep sense of value and belonging.

3) Unique: The unique factor came as the third influential factor, and recorded its highest scores in the evaluation of Sultan Abdul Samad Building, Jamek Mosque and Textile Museum. However, Agro Bank and Loke Yew Buildings received the lowest scores. In fact, what makes Sultan Abdual Samad Building a unique building is its notable clock tower which stands in contrast to the predominantly two-storey buildings in the surrounding area. What makes Jamek Mosque a unique building is its location at the convergence of two rivers as well as the shape of the domes.

A building can be considered as a landmark if it is in contrast with its surrounding background and have distinctive characteristics. A tree among a group of trees is difficult to consider as a landmark, whereas, a single tree in a desert is notable and unique. This situation can be applied in new cities, where many buildings are similar in design, shape and height. If one of these buildings was moved to another low-rise town, it will be easy to recognize the same building as a landmark (Clerici \& Mironowicz, 2009) because it stood in contrast with the surrounding environment (Lynch, 1960). For instance, a tourist from Nigeria thinks that Agro Bank is a unique building in reference to his background mental image. 
4) Meaningful: Meaningful is another factor that affects the connection between the observer and the landmark, thus enhancing a sense of belonging. Two religious buildings, namely Jamek Mosque and National Mosque received the highest scores in the meaningful factor as they represent the sensory element of the original image of Kuala Lumpur.

All landmarks should have a meaning to communicate with the observer at a personal level; and a same building may have different meanings and values (Clerici \& Mironowicz, 2009). For example, tourists visiting a religious icon such as the National Mosque in Kuala Lumpur may not be involved in worshipping but only an interest in the iconic design.

5) Legibility and Scale: Generally, legibility and scale are the two factors that received the lowest scores in the respondents' evaluation of landmarks as representing the original image of Kuala Lumpur. While, the KTMB Headquarters Railway Administrative Office received the highest scores in legibility and scale, following by Sultan Abdul Samad building (for legibility factor) and Dayabumi (for scale factor).

Although legibility and scale are very important in a building that features as a landmark, the survey result showed that legibility and scale received a lower value in the respondents' evaluation. This finding implies that having towers and high-rise buildings may not be so important in representing Kuala Lumpur as a unique city with a distinctive image and identity.

\subsection{Correlation between the Landmark Factors}

Table 5 shows the significant correlations between the seven landmark factors, with the exception of the meaningful factor. The meaningful value of a landmark is not related to other factors (such as design or color), but is associated with the activities that take place inside or around the landmark, which create a sense of meaning and belonging. Nevertheless, other factors relate to each other. For example, to consider a landmark as a unique, it should be in the same time memorable, historic and have a good design. This rule can be able for other factors also.

Table 5. Significant correlations between the 8 factors of landmark

\begin{tabular}{|c|c|c|c|c|c|c|c|c|}
\hline Factors & Unique & Memorable & Legible & Historic & Design & Scale & Meaningful & Color \\
\hline \multirow{2}{*}{ Unique } & & $0.619^{* *}$ & & $0.522 *$ & $0.624^{* *}$ & & & \\
\hline & & 0.008 & & 0.022 & 0.007 & & & \\
\hline \multirow{2}{*}{ Memorable } & $0.619 * *$ & & & $0.854 * *$ & & & & \\
\hline & 0.008 & & & 0.000 & & & & \\
\hline \multirow{2}{*}{ Legible } & & & & $-0.592 *$ & & $0.662^{* *}$ & & $0.496^{*}$ \\
\hline & & & & 0.012 & & 0.004 & & 0.043 \\
\hline \multirow{2}{*}{ Historic } & $0.522 *$ & $0.854^{* *}$ & $-0.592 *$ & & & $-0.587^{*}$ & & \\
\hline & 0.022 & 0.000 & 0.012 & & & 0.013 & & \\
\hline \multirow{2}{*}{ Design } & $0.624 * *$ & & & & & & & $0.590 *$ \\
\hline & 0.007 & & & & & & & 0.013 \\
\hline \multirow{2}{*}{ Scale } & & & $0.662 * *$ & $-0.587 *$ & & & & \\
\hline & & & 0.004 & 0.013 & & & & \\
\hline \multicolumn{9}{|l|}{ Meaningful } \\
\hline \multirow{2}{*}{ Color } & & & $0.496^{*}$ & & $0.590^{*}$ & & & \\
\hline & & & 0.043 & & 0.013 & & & \\
\hline
\end{tabular}

(*) correlation is significant at the 0.05 level (2-tail)

$(* *)$ correlation is significant at the 0.01 level (2-tail)

\section{Recommendations}

Results from this study show that the city of Kuala Lumpur has many interesting landmarks in the eyes of the tourists and local people. However, the city needs to focus on its historic and heritage buildings as well as its modern buildings to reflect a mixed image between modern and traditional lifestyles. This fusion image can be a distinguishing icon for Kuala Lumpur as compared to other developing cities in Southeast Asia. In addition, it 
will rebrand Kuala Lumpur in the eyes of the world as a city of multi culture and diverse society with deep enriched history.

It is important to redesign our cities by adopting the original architectural styles to create a distinctive city image and identity (Kuala Lumpur Structure Plan, 2020). A word of caution is that such redesigning our cities does not mean it would create a clear and legible image; rather than it would create a duplicating image with limited ability to interact with people of diverse backgrounds, educational level and interests. The range of notions and symbols that people can receive through interacting with the surrounding environment will be limited according to the limitation of messages that the city elements (landmarks) are able to transmit or send to the people as the receivers.

The findings of this paper lead to some recommendations to form a distinctive image in order to brand Kuala Lumpur as a city with a mixed image of modern and traditional buildings. In term of architecture, it is advisable to adopt and adapt a version of a Modern Islamic Architecture (i.e. example, Dayabumi Complex), to formulate a unique image of Kuala Lumpur as well as the flexibility to adopt new technologies and materials. Moreover, mix it with the Mughal Architecture (i.e. Jamek Mosque \& Sultan Abdul Samad building) to distinguish Kuala Lumpur's architecture from the others.

It is also important to emphasize on the macro image of the city, especially in the design to provide a variety of shapes and activities of buildings with a good harmony. This would avoid duplication and repetition of the same design or activity within the city, thus promoting buildings to be landmarks within the context of the city structure. Furthermore, it is imperative to enhance and develop the original activities in buildings and in the surrounding areas to create a strong relationship between the buildings as the main component of the city with the people.

\section{Conclusions}

This paper examines the image of Kuala Lumpur, specifically of selected landmarks in the core heritage area as perceived by tourists and local people. Results from the study showed that historic buildings such as Jamek Mosque, Sultan Abdul Samad Building and Old Railway Station obtained the highest evaluation scores from the respondents. Moreover, factors of design, historic and uniqueness are the main factors that influenced the respondents' evaluation. In terms of respondents' background, there is a significant difference between local and tourists based on the historic, unique, memorable and meaningful features of landmarks, as well as among ethnic groups based on the meaningful feature of landmarks.

An important issue to be considered about Kuala Lumpur's image is the city's ability to be a distinguishable from the other developing cities and reflect the reality that Kuala Lumpur is a mixed city between modern and traditional lifestyles. Forming a distinctive city image of Kuala Lumpur is not an easy task as it depends mainly on the manner of interactions between the people and their surrounding built environment. However, the differences in perceptions of landmarks by people of various backgrounds could enrich their city experiences through their long interactions with the city structure and spaces.

\section{References}

Askari, A. H. (2009). Public Evaluation of Historical Facades in the Vicinity of Dataran Merdeka, Kuala Lumpur. University Putra Malaysia.

Atik, D. Z., Çakir, H. K., \& Benian, E. (2009). The Importance Of City Image Elements Through Recognizing and Introducing of Cities: Edirne Example. Trakia Journal of Sciences, 7, 246-251.

Birgit, E., Volker, P., \& Marcel, C. (2009). Evaluation of User Variables in Topographic Feature Recall for the Informed Selection of Personalized Landmarks. Geoinformation and Cartography. Germany: Institute of Cartography and Geoinformatics, Leibniz University of Hannover.

Bunnell, T., Barter, P. A., \& Morshidi, S. (2002). City profile Kuala Lumpur metropolitan area-a globalizing city region. Cities, 19(5), 357-370. http://dx.doi.org/10.1016/S0264-2751(02)00036-7

Clerici, A., \& Mironowicz, I. (2009). Are landmarks essential to the city-its development? 14th International Conference on Urban Planning and Regional Development in the Information Society Geo Multimedia 2009, 22-25 April 2009.

Evers, H. D., \& Korff, R. (2000). Southeast Asian Urbanism: The Meaning and Power of Social Space. Singapore: Institute of Southeast Asian Studies.

Fee, C. V. (Ed.). (2007). The Encyclopedia of Malaysia, Architecture (Vol. VI). Kuala Lumpur: Archipelage Press. 
Gavris, A. (2010). Elements Of The Urban Image In Large Habitats Of Bucharest. Journal of Urban and Regional Analysis, II, 71-80.

Hasanuddin, L. (2004). Redefining Landmarks. Jurnal Alam Bina, 6, 66-76.

Ja'afar, N. H., \& Usman, I. M. (2009). Physical and Transportation Elements of Traditional Street in Malaysia. European Journal of Social Sciences, 9(4), 669-676.

Jansson, J., \& Power, D. (2006). The Image of The City-Urban Branding as Constructed Capabilities in Nordic City. Department of Social and Economic Geography, Uppsala University. Norway: Nordic Innovation Centre.

King, R. (2007). Re-writing the City: Putrajaya as Representation. Journal of Urban Design, 12(1), 117-138. http://dx.doi.org/10.1080/13574800601071337

Koseoglu, E., \& Onder, D. E. (2009). Defining Salient Elements of Environment and Memory Subjective and Objective Landmarks in Ayvalik, Turkey. In D. K. Marcus, \& J. Steen (Eds.), 7th International Space Syntax Symposium (p. 59). Stockholm.

Kritsonis, W. A. (2008). Research Design and Methods. Retrieved March 7, 2011, from http://www.slideshare.net/guestcclebaf/research-design-and-methodology

Kuala Lumpur Structure Plan 2020. Kuala Lumpur: Kuala Lumpur City Hall.

Lim, T. N., \& Tay, L. (2000). 80 Years of Architecture in Malaysia. PAM, Kuala Lumpur.

Lynch, K. (1960). The Image of the City. Cambridge, Massachusetts, United States of America : M I T Press.

Moser, S. (2009). Putrajaya: Malaysia's new federal administrative capital. Journal of Cities, 285-297.

Moughtin, C., Oc, T., \& Tiesdel, S. (1999). Urban Design: Ornament and Decoration. Oxford: Butterworth Architecture.

Nasar, J. L. (1990). The Evaluative Image of the City. Journal of the American Planning Association, 56(1), 41-53. http://dx.doi.org/10.1080/01944369008975742

Passini, R. (1992). Wayfinding in architecture (2nd ed.). New York: Van Nostrand Reinhold.

Ravenscroft, T. (2009, December 3). Modern Architecture In Kuala Lumpur, The Capital of Malaysia's Best Modern Buildings. $\quad$ Retrieved July 12, 2010, from http://www.suite101.com/content/modern-architecture-in-kuala-lumpur-a176351

Shamsuddin, S., \& Ujang, N. (2008). Making places: The role of attachment in creating the sense of place for traditional streets in Malaysia. Habitat International, 32, 399-409. http://dx.doi.org/10.1016/j.habitatint.2008.01.004

Skyscraper City. (2007, February 7). The Old Kuala Lumpur. Retrieved March 12, 2011, from http://www.skyscrapercity.com/showthread.php?t=438753

Thompson, E. (2007 ). Unsettling Absences: Urbanism in Rural Malaysia. Singapore: National University of Singapore Press.

Ujang, N. (2008). Place Attachment towards Shopping District in Kuala Lumpur City Center, Malaysia. University Putra Malaysia.

Zmudzinska, N. M. (2003). Searching for legible city form: Kevin Lynch's theory in contemporary perspective. Journal of Urban Technology, 10(3), 19-39. http://dx.doi.org/10.1080/1063073032000175390

\section{Note}

Note 1. The maximum number of responses for each influential landmark factor=120 respondents $\mathrm{x} 17$ landmarks $=2040$ counts

\section{Copyrights}

Copyright for this article is retained by the author(s), with first publication rights granted to the journal.

This is an open-access article distributed under the terms and conditions of the Creative Commons Attribution license (http://creativecommons.org/licenses/by/3.0/). 